\title{
A new form of autosomal dominant arthrogryposis
}

\author{
M M R Lai, M A Tettenborn, J G Hall, L J Smith, A C Berry
}

\begin{abstract}
We report a man and his son with congenital limb contractures, limitation of ocular movements, and an electroretinal abnormality. They appear to have an autosomal dominant form of arthrogryposis, distinguishable from other previously classified forms of this disorder.
\end{abstract}

Congenital joint contractures are a heterogeneous group of disorders usually known as 'arthrogryposis'. However, the term 'amyoplasia' is considered more appropriate when we describe a condition characterised by internal rotation of the arms with flexion at the wrists, bilateral talipes, and aplasia of limb muscles and their replacement by fibrous bands and fatty tissue.

Prenatal lack of muscle development leads to a reduction of intrauterine movements and therefore to contractures and absence of flexion creases in the fingers. ${ }^{1}$ Most cases are sporadic, but several forms of distal limb contracture follow an autosomal dominant pattern of inheritance. ${ }^{2}$

\section{Case reports}

CASE 1

The proband (fig 1), an intellectually normal 27 year old man, was born at term to a healthy 27 year old mother and 48 year old father. The patient has never known his father, who was reported by his wife to be a healthy and successful professional.

SE Thames Regional Genetics Centre, 8th Floor, Guy's Tower, Guy's Hospital, London SE1 9RT.

M M R Lai, L J Smith, A C Berry

District General Hospital, King's Drive, Eastbourne, East Sussex BN21 2 UD.

M A Tettenborn

Department of Medical Genetics, University of British Columbia, Shaughnessy Site, 4500 Oak Street, Vancouver, BC, Canada V6H 3NI

J G Hall

Correspondence to Dr Lai.

Received for publication 24 January 1991

Accepted for publication 19 February 1991.
Bilateral club feet were noted at birth and required multiple surgical interventions, including tibial osteotomies and ankle fusion.

On examination, he had sloping shoulders, a stiff trunk, and a mild pectus deformity. His knees, hips, and shoulders were limited in movement. His height was $166 \mathrm{~cm}$, weight $85.5 \mathrm{~kg}$, and head circumference $54 \mathrm{~cm}$.

He had limited rotation of his forearms and his elbows lacked $20^{\circ}$ of extension. When making a fist there was overlap of the fingers and there was also limitation of extension of the wrists. He had deep dimples on the elbows, shoulders, and ankles.

The facies was somewhat immobile and he had a square chin with a midline dimple and a high palate. He showed some degree of ptosis on the right eye which was 'lazy', turning out, and not focusing. $\mathrm{He}$

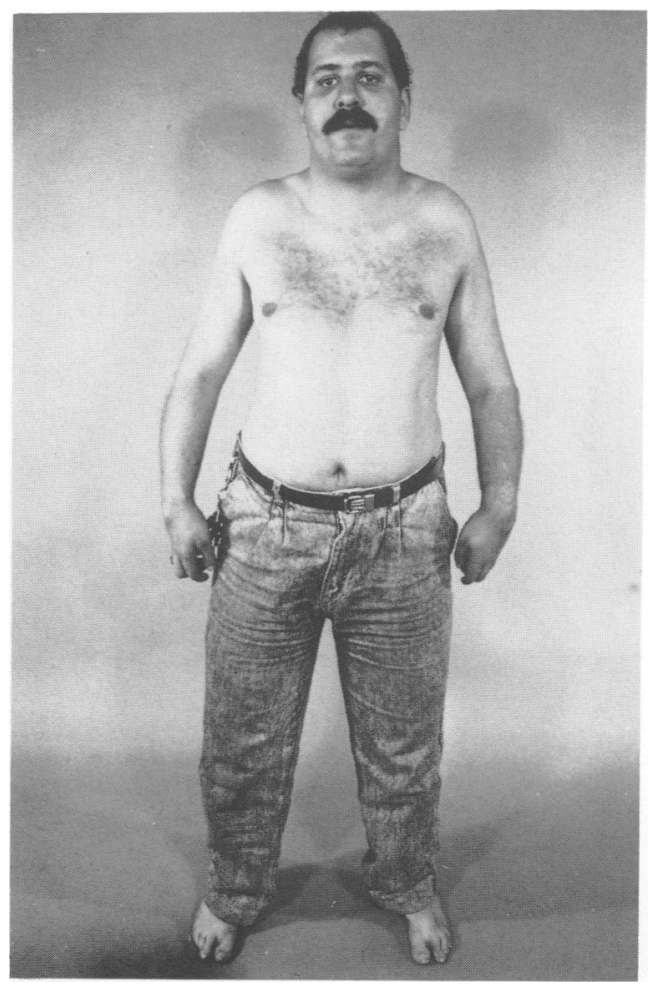

Figure 1 Case 1. 
was unable to move his eyes laterally in either direction or up and down. Visual acuity, after correction with glasses, was $6 / 9$. He was otherwise well.

In view of the ophthalmoplegia and muscle involvement, an ophthalmological assessment was undertaken. He had normal retinal vessels and pigmentation, but the electroretinogram (ERG) was abnormal with no rise on dark adaptation, thus suggesting a tapetoretinal degeneration. The flicker response was normal.

When initially seen, a diagnosis of classical amyoplasia was made and he was reassured that his offspring were unlikely to be affected. His first son is entirely normal. The second is described below.

\section{CASE 2}

The second son of case 1 (fig 2) was born at 37 weeks after an unremarkable pregnancy. The mother was 34 years old and the father 24 at the time of his birth. Fetal movements were seen on ultrasound and normally felt by the mother. At birth his feet and hands were noted to have contractures that needed surgery at 9 weeks. His hands were stiff with

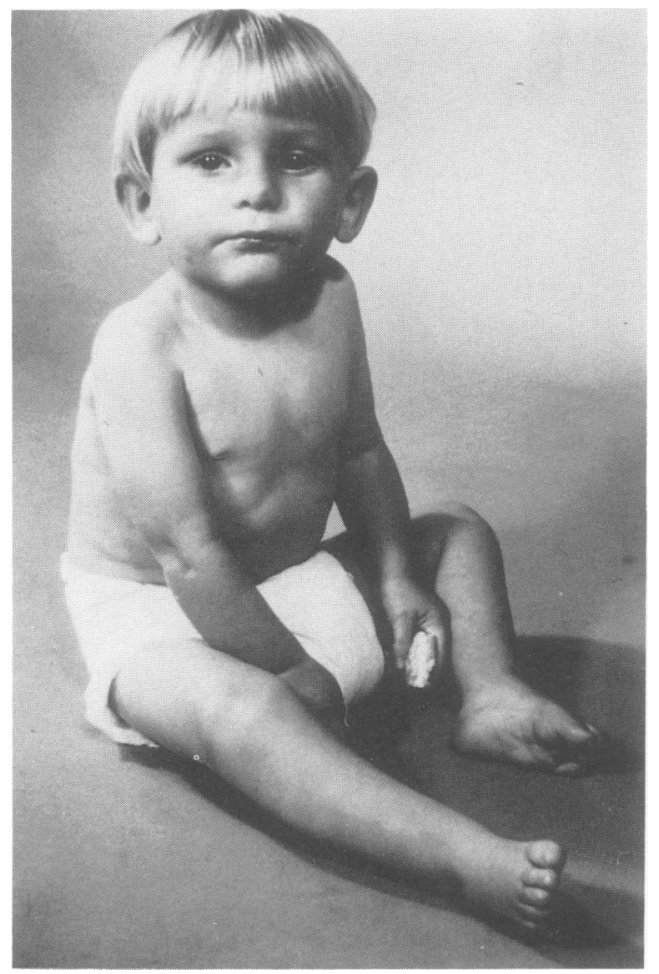

Figure 2 Case 2. long fingers, and the shoulders were stiff and internally rotated. The elbows were normal. He responded well to physiotherapy.

On examination at 1 year of age, he was a lively baby, with a triangular facies, prominent ears which lacked the secondary fold, deep set eyes, mild ptosis, and some limitation of lateral and medial eye movements. The palate was normal. He had dimples over his shoulders, knees, elbows, and buttocks.

$\mathrm{He}$ had an increased AP chest diameter, with widely spaced nipples. He lacked rotation of the elbows and his shoulders were hunched and his trunk stiff. He had camptodactyly (fig 3 ), limitation of full extension of the wrist, and some ulnar drift when opening his hands. His fingers had no interphalangeal creases and the palmar creases were poorly formed.

$\mathrm{He}$ also had bilateral inguinal hernias. $\mathrm{He}$ was seen again at the age of 18 months. His height was on the 75 th centile, weight on the 10 th centile, and head circumference on the 50th centile. His mental development was appropriate for his age.

At the ophthalmological assessment, the ERG showed a formed response with moderate rise on dark adaptation, but a progressive retinal degeneration could not be excluded in view of the very young age of the patient.

\section{Discussion}

The type and distribution of the joint fixation and contractures are so similar in the father and son that they must be considered to be the same condition.

Among the most well recognised conditions with contractures of the distal joints are Gordon syndrome, ${ }^{3}$ where the palate is usually cleft, and Beal syndrome, ${ }^{4}$ where the fingers are very long and the ears abnormally shaped with large and floppy helices. Our patients do not fit into either of these syndromes as they had proximal as well as distal joint limitation. They show some similarity to a

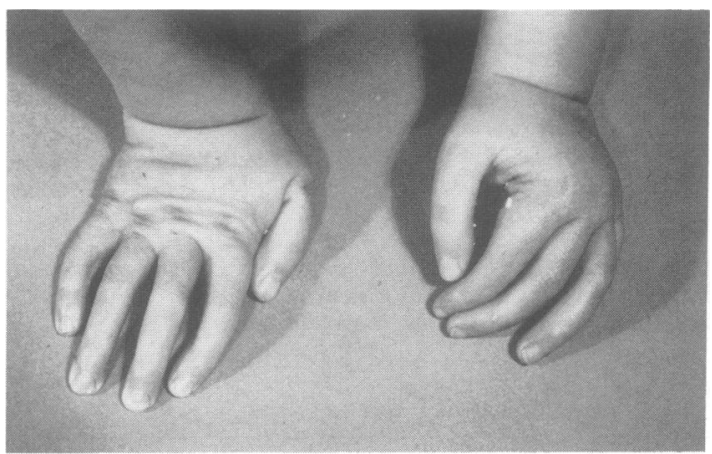

Figure 3 Hands of case 2 showing camptodactyly. 
condition classified as arthrogryposis IIB by Hall et $a .^{2}$ This is mainly distinguished by shortness of stature and neck, immobile facies, epicanthic folds, and distal contractures. In addition there is decreased ocular mobility, slight ulnar deviation of the hands, absent distal phalangeal creases, and decreased mobility of other major joints.

Our patients fulfil only some criteria for a diagnosis of arthrogryposis type IIB, as neither of them show short stature, short neck, or epicanthic folds, and their proximal joints are more involved.

Our two patients appear to have a new autosomal dominant form of arthrogryposis characterised by distal contractures, stiffness of the trunk, limitation of movement of some proximal joints, ptosis, ophthalmoplegia, and possible retinal involvement in the father. The absence of abnormalities on ERG in the son does not exclude the possibility of a progressive retinal degeneration.

As the son seems to be less affected than his father, this disorder might be progressive and this, together with the ophthalmoplegia, would be suggestive of a mitochondrial disorder. In view of the paucity of muscle bulk on clinical examination, an open biopsy would be necessary to obtain sufficient specimen. We felt this was not justified because of the risks associated with general anaesthesia in this group of patients. ${ }^{5}$

Usually, the presence of proximal joint contractures in the pattern seen in these two cases is suggestive of a sporadic form of arthrogryposis. This family indicates that dominant inheritance must be considered when distal contractures are associated with limited movements of the proximal joints and with ptosis and ophthalmoplegia.

We wish to thank Mr D M Calver of the Ophthalmology Department of Guy's Hospital, London, and Mr K R Ross of the Orthopaedic Department of Eastbourne District General Hospital for their cooperation.

1 Hall JG. In utero movement and use of limbs are necessary for normal growth: a study of individuals with arthrogryposis. Prog Clin Biol Res 1985;200:155-62.

2 Hall JG, Reed SD, Greene G. The distal arthrogryposes: delineation of new entities. Review and nosologic discussion. Am f Med Genet 1982;11:185-239.

3 Halal F, Fraser FC. Camptodactyly, cleft palate and club foot (the Gordon syndrome): a report of a large pedigree. $\mathcal{f}$ Med Genet 1979;16:149-50.

4 Beal RK, Hecht F. Congenital contractural arachnodactyly: a heritable disorder of connective tissue. $f$ Bone foint Surg $[A m] 1971 ; 53: 987-93$.

5 Froster-Iskenius UG, Waterson JR, Hall JG. A recessive form of congenital contractures and torticollis associated with malignant hyperthermia. $\mathcal{F}$ Med Genet 1988;25:104-12. 